Published in final edited form as:

J Perinatol. 2016 June ; 36(6): 453-458. doi:10.1038/jp.2016.5.

\title{
Response to dopamine in prematurity: a biomarker for brain injury?
}

\author{
Zachary A. Vesoulis ${ }^{1}$, Nathalie El Ters ${ }^{1}$, Allison Foster ${ }^{1}$, Shamik B. Trivedi ${ }^{1}$, Steve M. Liao ${ }^{1}$, \\ and Amit M. Mathur ${ }^{1}$ \\ ${ }^{1}$ Division of Newborn Medicine, Edward Mallinckrodt Department of Pediatrics, Washington \\ University School of Medicine, St. Louis, MO, USA
}

\begin{abstract}
Objective-Identify factors associated with responsiveness to dopamine therapy for hypotension and the relationship to brain injury in a cohort of preterm infants.

Study Design-The pharmacy database at St. Louis Children's Hospital was retrospectively queried to identify infants who (a) were born $<28$ weeks gestation between 2012-14, (b) received dopamine, and (c) had blood pressure measurements from an umbilical arterial catheter. A control group was constructed from contemporaneous infants who did not receive dopamine. Mean arterial blood pressure (MABP) at baseline, $1 \mathrm{~h}$ and $3 \mathrm{~h}$ after initiating dopamine were obtained for each dopamine-exposed infant. MABP measurements at matched time points were obtained in the control group.
\end{abstract}

Results-Sixty-nine dopamine-treated and forty-five control infants were included. Mean $\triangle \mathrm{MABP}$ at $3 \mathrm{~h}$ was $4.5 \pm 6.3 \mathrm{~mm}$ of $\mathrm{Hg}$ for treated infants versus $1 \pm 2.9$ for the control. Median dopamine starting dose was $2.5 \mu \mathrm{g} / \mathrm{kg} / \mathrm{min}$. Dopamine-treated infants were less mature and lower birth weight while also more likely to be intubated at $72 \mathrm{~h}$, diagnosed with intraventricular hemorrhage (IVH), and to die. Failure to respond to dopamine was associated with greater likelihood of developing IVH (OR 5.8, 95\% CI 1.1-42.3), while a strong response ( $\triangle \mathrm{MABP}>10$ $\mathrm{mmHg}$ ) was associated with a reduction in risk of IVH (OR 0.1, 95\% CI 0.01-0.8).

Conclusions-Low-moderate dose dopamine administration results in modest blood pressure improvements. A lack of response to dopamine is associated with a greater risk of IVH while a strong response is associated with a decreased risk. Further research into underlying mechanisms and management strategies is needed.

\section{Keywords}

blood pressure; intraventricular hemorrhage; hypotension

Users may view, print, copy, and download text and data-mine the content in such documents, for the purposes of academic research, subject always to the full Conditions of use:http://www.nature.com/authors/editorial_policies/license.html\#terms

Address correspondence to: Zachary A. Vesoulis, MD, Washington University School of Medicine, 1 Children's Place, St. Louis, MO USA 63110, Phone/Fax: 314-286-1524 / 314-454-4633, vesoulis_z@kids.wustl.edu.

CONFLICT OF INTEREST STATEMENT

The authors declare no conflicts of interest. 


\section{INTRODUCTION}

The diagnosis of hypotension in very preterm infants has long confounded neonatologists. Early studies ${ }^{1,2}$ formed the basis for the now commonly accepted practice ${ }^{3}$ of setting the lower acceptable limit of mean arterial blood pressure (MABP) in $\mathrm{mmHg}$ equal to the estimated gestational age (EGA) in weeks. An alternative definition has been proposed, using MABP < $30 \mathrm{mmHg}$ as the threshold, given evidence that the risk of intraventricular hemorrhage (IVH) increases proportionally to the time spent with MABP below 30 mmHg. ${ }^{4-9}$

Given the paucity and heterogeneity of normative data in this very preterm population, there is considerable variance in management of hypotension ${ }^{10}$; approximately $55-82 \%$ of infants born before 28 weeks EGA receive some form of therapy for hypotension, generally volume resuscitation and/or vasoactive medications, the most common of which is dopamine. ${ }^{11,12}$

Dopamine, a non-selective adrenergic agonist, has been widely used for the treatment of hypotension in preterm infants for several decades $7,13,14$ and has been compared to a number of other anti-hypotensive regiments, demonstrating that dopamine is superior, or at least equivalent, with a more limited side-effect profile. ${ }^{15-25}$ However, there is a relative lack of data about isolated use of dopamine in the hypotensive preterm infant. To date, there has been only one trial of dopamine vs. placebo, the results of which are limited by small sample size. $^{26}$

In this study we aim to describe (a) clinical factors associated with the use of dopamine in a cohort of very preterm infants in comparison to a contemporaneous control group that was not treated with dopamine, (b) determinants of blood pressure response to dopamine, and (c) differences in the incidence of IVH in hypotensive patients who respond versus those who do not respond to dopamine treatment.

\section{METHODS}

\section{Subject identification}

This study was conducted in the neonatal intensive care unit (NICU) at St. Louis Children's Hospital, a 75-bed, Level IV unit located in an urban setting. The pharmacy database system was queried to identify all admitted infants who were prescribed dopamine infusions between 2012 and 2014. Our general institutional practice is to consider dopamine initiation when either (a) the MABP $<$ EGA in weeks, (b) there is poor urine output $(<1 \mathrm{~mL} / \mathrm{kg} / \mathrm{h})$ and/or (c) there are clinical signs of poor perfusion (prolonged central capillary refill time, tachycardia). Infants were included if (a) they were born before 28 completed weeks of gestation, (b) a dopamine infusion was started within the first 72 hours after birth, and (c) they had blood pressure measurements made by umbilical arterial catheter.

A second cohort of infants was developed as a control group. This group consisted of infants who were recruited as a part of a prospective physiologic monitoring study conducted at the same site during the same time period. Infants were included if (a) they were born before 28 completed weeks of gestation, (b) a dopamine infusion was NOT initiated in the first 72 
hours after birth and (c) they had blood pressure measurements made by umbilical arterial catheter.

Infants were excluded if they received more than one inotropic agent or postnatal corticosteroids during the study window.

The study protocol was reviewed and approved by the Human Research Protection Office at the Washington University School of Medicine.

\section{Data collection}

Clinical factors-A comprehensive set of clinical factors were abstracted from the medical chart including gestational age at birth, sex, race, birth weight, Apgar scores, delivery method, antenatal magnesium sulfate and/or steroid exposure, histologic diagnosis of chorioamnionitis, fentanyl exposure in the neonatal period, presence of PDA requiring treatment, method of respiratory support at 72 hours (invasive or non-invasive), and survival to discharge. Severity of illness for each infant was measured using the CRIB-II index developed by Parry et al. ${ }^{27}$

Dopamine data-Postnatal age at infusion start as well as infusion dosage ( $\mu \mathrm{g} / \mathrm{kg} / \mathrm{min})$ at the start and end of the study window were recorded for all dopamine-exposed infants. The administration of volume expansion prior to dopamine infusion was also noted.

Blood pressure data-Umbilical arterial lines (3.5 French Argyle single lumen umbilical vessel catheter, Covidien, Mansfield, MA) were placed, shortly after hospital admission, in the high-lying position, located between the sixth and eighth thoracic vertebrae on chest radiograph as per standard clinical practice. Arterial blood pressure was then determined by use of a pressure transducer connected to the patient monitor (Intellivue MP70, Philips Medical, Andover, MA).

For the dopamine-exposed group, mean arterial blood pressure (MABP) values were obtained at the time of dopamine initiation as well as one and three hours after initiation. In order to provide an equivalent comparison, MABP measurements from a similar distribution of postnatal ages were obtained from the control group as well as follow-up measurements at one and three hours after the initial time point.

Neuroimaging data-The presence (or absence) of IVH as well as severity grade was determined from screening cranial ultrasounds performed during the first three days of life, and a follow-up study performed at 7-10 days of life, which were scored using the standard algorithm outlined by Papile et al. ${ }^{28}$.

\section{Statistical methodology}

A comparison of perinatal factors was made between those who received dopamine and the control group using the Mann-Whitney U-test for continuous variables and a two-sided Fisher's Exact test for categorical variables. A repeated measures ANOVA design was used to examine effect of time on blood pressure values, both within- and between-groups. 
Predictors of dopamine treatment success (defined as achieving a MABP at 3 hours $\geq E G A$ in weeks), non-response (defined as MABP at 3 hours $\leq \mathrm{MABP}$ at start) and super response ( $\triangle \mathrm{MABP}$ at 3 hours $>10 \mathrm{mmHg}$ ) were evaluated using binary logistic regression models. The association between dopamine treatment and the development of IVH was assessed using binary logistic regression with the presence or absence of IVH as the outcome while controlling for factors known to be associated with IVH (EGA, birthweight, and antenatal corticosteroids ${ }^{29}$ ). In all cases, the correlation between predictors was assessed using the variance inflation factor (VIF), a measure of the degree of multicollinearity where VIF $>5$ is indicative of highly collinear predictors.

Statistical analysis including descriptive statistics and regression modeling were conducted using R version 3.2.1 (R Project for Statistical Computing, Vienna, Austria) and Minitab version 17.0 (Minitab Inc., State College, PA).

\section{RESULTS}

\section{Descriptive statistics}

Between 2012 and 2014, 2318 infants were admitted to the NICU at St. Louis Children's Hospital. Of those, 69/2318 (3\%) met the inclusion criteria ( $<28$ weeks gestation at birth with a UAC and started on dopamine in the first 72 hours of life) and comprise the dopamine-exposed cohort. During that same time period, eighty-six premature infants $<28$ weeks were recruited for a prospective monitoring study and 46/86 (53\%) of those infants met these inclusion criteria for the non-exposed control cohort. Descriptive statistics for each group as well as a between-groups comparison is shown in Table 1. Of note, the dopamineexposed infants were less likely to be born to mothers with chorioamnionitis ( $\mathrm{p}<0.01$ ), had higher CRIB-II scores $(\mathrm{p}<0.01)$, were more likely to be diagnosed with IVH $(\mathrm{p}<0.01)$, and more likely to die during hospitalization $(\mathrm{p}=0.01)$.

\section{Blood pressure trajectory}

Approximately 23\% of infants in the dopamine-exposed group received a bolus of NS (normal saline) prior to initiation of dopamine and the median starting and ending dose of dopamine was $2.5 \mu \mathrm{g} / \mathrm{kg} / \mathrm{min}$. Infants who received dopamine had a lower MABP, when compared to those who did not receive dopamine at the start (24.6 vs. $33.8 \mathrm{mmHg})$, one hour later (27.6 vs. $33.6 \mathrm{mmHg}$ ) and three hours later (29.1 vs. $34.4 \mathrm{mmHg}$ ) (Table 2). This between-groups difference was statistically significant across all time points $(\mathrm{F}=103.78$, $\mathrm{p}<0.01)$. There was no significant change in blood pressure over the three-hour study window for those infants who did not receive dopamine $(\mathrm{F}=0.24, \mathrm{p}=0.79)$.

As would be expected, there was a significant increase in blood pressure over the course of the three-hour study window in the dopamine-exposed cohort $(\mathrm{F}=8.64, \mathrm{p}<0.01)$. The distribution of blood pressures in the dopamine treatment group gradually shifted, going from the right skewed distribution centered around $24 \mathrm{mmHg}$ at the start of treatment, as shown in Figure 1, Panel A to the more normal distribution centered around $30 \mathrm{mmHg}$ at three hours of treatment, shown in Figure 1, Panel C. 


\section{Dopamine treatment success and non-response}

No factors could be identified which predicted success of dopamine treatment, defined as achieving MABP $\geq E G A$, three hours after initiation of dopamine (Table 3). A lower 5minute Apgar score was associated with non-response to dopamine, defined as no change or decrease in blood pressure three hours after initiation of dopamine infusion (OR 0.6, 95\% CI $0.4-0.8$, Table 3).

\section{Dopamine super-response}

Twenty-one of the sixty-nine dopamine-exposed infants (30\%) met the criteria for superresponse, defined as $\triangle \mathrm{MABP}>10 \mathrm{mmHg}$ from the baseline 3 hours after treatment start. Increasing 5-minute Apgar scores (OR 1.6, 95\% CI 1.1-2.5), presence of chorioamnionitis (OR 11.4, 95\% CI 1.3-102.7), and increasing dopamine dose (OR 2.1, 95\% CI 1.2-3.4) were independently associated with an increased likelihood of a super-response to dopamine. Increasing gestational age was associated with a decreased likelihood of developing a super-response (OR $0.5,95 \%$ CI $0.3-0.9$ ). Although statistically significant, the differences in the mean starting ( $3.3 \mathrm{vs} 3.9 \mu \mathrm{g} / \mathrm{kg} / \mathrm{min}$ ) or ending ( $3.3 \mathrm{vs} 4.4 \mu \mathrm{g} / \mathrm{kg} / \mathrm{min}$ ) dose of dopamine between super-responders and the remainder of the group is of minimal clinical significance. The output of the full model is shown in Table 3.

\section{Predictors of IVH}

Fentanyl exposure (OR 10.4, 95\% CI 1.7-65.9) and lack of response to dopamine at 3 hours (OR 5.8, 95\%CI 1.1-42.3) were independently associated with a greater likelihood of IVH of any grade. A complete course of antenatal steroids (OR 0.1 95\% CI 0.01-0.6), Caesarean delivery (OR $0.195 \%$ CI 0.01-0.8), and death (OR $0.195 \%$ CI 0.01-0.6) were associated with decreased likelihood of IVH of any grade. In contrast, only fentanyl exposure was associated with an increased likelihood of high-grade IVH (OR 5.9 95\% CI 1.4-25.4) while "dopamine super-responder" status was associated with a lower likelihood of high-grade IVH (OR 0.1, 95\% CI 0.01-0.8). A complete model for predictors of IVH is shown in Table 4.

\section{DISCUSSION}

Our data confirm that dopamine, at low-to-moderate doses (1-7.5 $\mu \mathrm{g} / \mathrm{kg} / \mathrm{min})$, is effective at increasing the MABP as there is a statistically significant improvement $(4.5 \pm 6.3 \mathrm{mmHg})$ in blood pressure following the first few hours of dopamine treatment in hypotensive preterm infants. This effect is sufficient to halve the proportion of infants with MABP < EGA, from $60 \%$ at treatment start to only $30 \%$ at one hour. Additional treatment time does not increase the likelihood of success.

Although of similar gestational age and birth weight, infants who were treated with dopamine were sicker, as evidenced by higher CRIB-II scores, and were more likely to suffer long-term consequences, in the form of death and intraventricular hemorrhage, findings in line with a priori expectations. Interestingly, only $60 \%$ of infants who received dopamine were hypotensive by the MABP < EGA criteria at the start of treatment. However, 
given the retrospective nature of the study, it is not possible to intuit the intention behind initiating treatment and may include factors other than the blood pressure.

Many of the factors that are associated with the development of IVH in this study have been noted by other researchers, including antenatal corticosteroids ${ }^{30}$, delivery method ${ }^{30,31}$ as well as opioid exposure. ${ }^{32,33}$ The data in this study reveal a new, previously undescribed association between IVH and the lack of response to dopamine, rather the measured blood pressure at the time of treatment initiation. While no particular indicators for treatment success could be identified, a more extensive delivery room resuscitation (as indirectly indicated by lower Apgar scores at 5 minutes) is associated with an increased likelihood of treatment failure. This treatment failure is, in turn, associated with an increased likelihood of developing IVH, suggesting a correlation between the two, although establishing cause and effect is not possible given the retrospective nature of these data.

A dysfunctional cerebrovascular autoregulatory system, which is not able to properly dampen blood pressure fluctuations in a sick, preterm infants may be the common denominator in both instances. Cerebral autoregulation is a complex system and disruption may arise from several causes including developmental immaturity, hypotension, and ischemic injury. Previous work has demonstrated clear differences in the ability to dampen blood pressure fluctuations across gestational ages. ${ }^{34}$ Furthermore, Soul et al ${ }^{35}$ and Noori et al. ${ }^{36}$ amongst others, have highlighted this potential vulnerability, implicating altered cerebral autoregulation in the setting of hypotension as a key factor for the pathogenesis of IVH. Indeed, each point increase in the Apgar score is associated with a 40\% reduction in the likelihood of dopamine treatment failure, further underscoring the potential role perinatal ischemia may play in autoregulatory dysfunction.

It is difficult to disentangle from these data however, whether an initial ischemic insult leads to autoregulatory dysfunction and hypotension or whether hypotension itself is the inciting factor, contributing to ischemia and subsequent autoregulatory failure. There is evidence in adults that hypotension exacerbates pre-existing autoregulatory failure ${ }^{37}$, although there has been no convincing evidence of the same in the preterm infant population. Regardless, there is likely a strong feedback loop between these factors that exacerbates the initial injury. Nevertheless, it should again be emphasized that the results of this study reflect an association and cannot definitively identify the underlying mechanism.

We also found a decreased use of dopamine in infants who were born to mothers with pathologically confirmed chorioamnionitis. Relative insufficiency of the hypothalamicpituitary-adrenal (HPA) axis, which has been described extensively by Watterburg et al. ${ }^{38}$ in the context of bronchopulmonary dysplasia, may also provide a unifying mechanism, in the form of adrenergic receptor downregulation, to explain the lack of response to dopamine in some infants. However, the reasons for the decreased use of dopamine in infants born to mothers with chorioamnionitis remain unclear. Cortisol levels were not measured in any of the infants in this study.

Indeed, even amongst those infants who received dopamine, the subset of infants who displayed a robust response ("super-responders") had a decreased likelihood of developing 
IVH, suggesting that the response to dopamine may serve as a biomarker for the function of the autoregulatory system and the risk for IVH.

\section{Strengths \& limitations}

Given the nature of medication dispensation at our institution, it is unlikely that any infants who received dopamine were missed, as all dopamine syringes are prepared in the central pharmacy and are done so only after an electronic order has been placed.

Of note, the IVH prediction model did not demonstrate a statistically significant association between rates of IVH and EGA. Although the risk of IVH decreases with advancing maturity, epidemiologic data ${ }^{39}$ demonstrates significant overlap in the incidence of IVH between infants born at 23 weeks (35\% incidence, 95\% CI 13-58\%) and those born at 28 weeks (12\% incidence, $95 \%$ CI 9-15\%) making it difficult to statistically distinguish differences in a cohort with a relatively tight gestational age distribution such as this one. Furthermore, the regression model included other factors also associated with the development of IVH (birth weight, antenatal steroids, delivery method, sex and race) which likely decreased the impact of EGA on the overall model.

There are, however, several limitations to this current study. One major limitation is the use of limited number of fixed time points of blood pressure measurement (as opposed to continuous measurement) and a limited follow-up time period. This study is also limited by its retrospective nature and the potential for introduction of unknown bias. These preliminary findings should be rigorously evaluated in the setting of clinical trial in order to test their validity. Nevertheless, to our knowledge, this report represents the largest report of short-term outcomes in dopamine-exposed preterm infants in comparison to a contemporaneously collected control cohort.

\section{Future directions}

A recent international trial based in Ireland, the UK and the EU

(ClinicalTrials.govNCT01482559) was opened to investigate the impact of dopamine versus placebo with the primary outcome measure of survival to 36 weeks corrected age with severe brain injury and a secondary outcome of survival without moderate or severe long term neurodevelopmental disability. Collection of primary outcome data is not expected until 2018.

Given the potential implication that hypotension, in association with vasoregulatory and autoregulatory dysfunction, is a contributing factor for brain injury, and thus neurodevelopmental impairment, research should continue in order to better develop a strategy for identifying infants most likely to benefit from treatment, initiating treatment in the appropriate timeframe and identifying the target blood pressures for escalation of therapy. Our findings further indicate the urgent need for a randomized controlled trial using continuous blood pressure monitoring, investigation of the HPA axis and frequent surveillance for IVH. 


\section{Acknowledgments}

The authors wish to thank Brandy Zeller, PharmD and Caren Livisky, PharmD for their assistance in identifying infants using the pharmacy database system and Anthony Barton for his tireless efforts in recruitment and data management.

Sources of support:

1. Intellectual and Developmental Disabilities Research Center (IDDRC) at Washington University (NIH/NICHD P30 HD062171)

2. Washington University Institute of Clinical and Translational Sciences KL2 Training Program (NIH/NCATS KL2 TR000450)

3. The Barnes-Jewish Hospital Foundation and the Washington University Institute of Clinical and Translational Sciences Clinical and Translational Funding Program (NIH/NCATS UL1 TR000448)

\section{REFERENCES}

1. Zubrow AB, Hulman S, Kushner H, Falkner B. Determinants of blood pressure in infants admitted to neonatal intensive care units: a prospective multicenter study. Philadelphia Neonatal Blood Pressure Study Group. J Perinatol. 1995; 15:470-479. [PubMed: 8648456]

2. Cunningham S, Symon AG, Elton RA, Zhu C, McIntosh N. Intra-arterial blood pressure reference ranges, death and morbidity in very low birthweight infants during the first seven days of life. Early Hum Dev. 1999; 56:151-165. [PubMed: 10636594]

3. Development of audit measures and guidelines for good practice in the management of neonatal respiratory distress syndrome. Report of a Joint Working Group of the British Association of Perinatal Medicine and the Research Unit of the Royal College of Physicians. Arch Dis Child. 1992; 67:1221-1227. [PubMed: 1444567]

4. Bada HS, Korones SB, Perry EH, Arheart KL, Ray JD, Pourcyrous M, et al. Mean arterial blood pressure changes in premature infants and those at risk for intraventricular hemorrhage. J Pediatr. 1990; 117:607-614. [PubMed: 2213390]

5. Miall-Allen VM, de Vries LS, Whitelaw AG. Mean arterial blood pressure and neonatal cerebral lesions. Arch Dis Child. 1987; 62:1068-1069. [PubMed: 3314723]

6. Murphy DJ, Hope PL, Johnson A. Neonatal risk factors for cerebral palsy in very preterm babies: case-control study. BMJ. 1997; 314:404-408. [PubMed: 9040385]

7. Seri I, Rudas G, Bors Z, Kanyicska B, Tulassay T. Effects of low-dose dopamine infusion on cardiovascular and renal functions, cerebral blood flow, and plasma catecholamine levels in sick preterm neonates. Pediatr Res. 1993; 34:742-749. [PubMed: 8108186]

8. Munro MJ, Walker AM, Barfield CP. Hypotensive extremely low birth weight infants have reduced cerebral blood flow. Pediatrics. 2004; 114:1591-1596. [PubMed: 15574619]

9. Børch K, Lou HC, Greisen G. Cerebral white matter blood flow and arterial blood pressure in preterm infants. Acta Paediatr Oslo Nor 1992. 2010; 99:1489-1492.

10. Al-Aweel I, Pursley DM, Rubin LP, Shah B, Weisberger S, Richardson DK. Variations in prevalence of hypotension, hypertension, and vasopressor use in NICUs. J Perinatol. 2001; 21:272-278. [PubMed: 11536018]

11. Batton B, Li L, Newman NS, Das A, Watterberg KL, Yoder BA, et al. Use of antihypotensive therapies in extremely preterm infants. Pediatrics. 2013; 131:e1865-e1873. [PubMed: 23650301]

12. Laughon M, Bose C, Allred E, O'Shea TM, Van Marter LJ, Bednarek F, et al. Factors associated with treatment for hypotension in extremely low gestational age newborns during the first postnatal week. Pediatrics. 2007; 119:273-280. [PubMed: 17272616]

13. Seri I. Cardiovascular, renal, and endocrine actions of dopamine in neonates and children. J Pediatr. 1995; 126:333-344. [PubMed: 7869189]

14. Seri I, Tulassay T, Kiszel J, Machay T, Csömör S. Cardiovascular response to dopamine in hypotensive preterm neonates with severe hyaline membrane disease. Eur J Pediatr. 1984; 142:3-9. [PubMed: 6714257] 
15. Filippi L, Pezzati M, Poggi C, Rossi S, Cecchi A, Santoro C. Dopamine versus dobutamine in very low birthweight infants: endocrine effects. Arch Dis Child Fetal Neonatal Ed. 2007; 92:F367F371. [PubMed: 17329276]

16. Hentschel R, Hensel D, Brune T, Rabe H, Jorch G. Impact on blood pressure and intestinal perfusion of dobutamine or dopamine in hypotensive preterm infants. Biol Neonate. 1995; 68:318324. [PubMed: 8835086]

17. Klarr JM, Faix RG, Pryce CJ, Bhatt-Mehta V. Randomized, blind trial of dopamine versus dobutamine for treatment of hypotension in preterm infants with respiratory distress syndrome. $\mathrm{J}$ Pediatr. 1994; 125:117-122. [PubMed: 8021760]

18. Greenough A, Emery EF. Randomized trial comparing dopamine and dobutamine in preterm infants. Eur J Pediatr. 1993; 152:925-927. [PubMed: 8276025]

19. Rozé JC, Tohier C, Maingueneau C, Lefèvre M, Mouzard A. Response to dobutamine and dopamine in the hypotensive very preterm infant. Arch Dis Child. 1993; 69:59-63. [PubMed: 8346957]

20. Miall-Allen VM, Whitelaw AG. Response to dopamine and dobutamine in the preterm infant less than 30 weeks gestation. Crit Care Med. 1989; 17:1166-1169. [PubMed: 2791595]

21. Pellicer A, Valverde E, Elorza MD, Madero R, Gayá F, Quero J, et al. Cardiovascular support for low birth weight infants and cerebral hemodynamics: a randomized, blinded, clinical trial. Pediatrics. 2005; 115:1501-1512. [PubMed: 15930210]

22. Valverde E, Pellicer A, Madero R, Elorza D, Quero J, Cabañas F. Dopamine versus epinephrine for cardiovascular support in low birth weight infants: analysis of systemic effects and neonatal clinical outcomes. Pediatrics. 2006; 117:e1213-e1222. [PubMed: 16717120]

23. Bourchier D, Weston PJ. Randomised trial of dopamine compared with hydrocortisone for the treatment of hypotensive very low birthweight infants. Arch Dis Child Fetal Neonatal Ed. 1997; 76:F174-F178. [PubMed: 9175947]

24. Gill AB, Weindling AM. Randomised controlled trial of plasma protein fraction versus dopamine in hypotensive very low birthweight infants. Arch Dis Child. 1993; 69:284-287. [PubMed: 8215566]

25. Lundstrøm K, Pryds O, Greisen G. The haemodynamic effects of dopamine and volume expansion in sick preterm infants. Early Hum Dev. 2000; 57:157-163. [PubMed: 10735462]

26. Cuevas L, Yeh TF, John EG, Cuevas D, Plides RS. The effect of low-dose dopamine infusion on cardiopulmonary and renal status in premature newborns with respiratory distress syndrome. Am $\mathrm{J}$ Dis Child 1960. 1991; 145:799-803.

27. Parry G, Tucker J, Tarnow-Mordi W. CRIB II: an update of the clinical risk index for babies score. Lancet. 2003; 361:1789-1791. [PubMed: 12781540]

28. Papile LA, Burstein J, Burstein R, Koffler H. Incidence and evolution of subependymal and intraventricular hemorrhage: a study of infants with birth weights less than 1,500 gm. J Pediatr. 1978; 92:529-534. [PubMed: 305471]

29. Köksal N, Baytan B, Bayram Y, Nacarküçük E. Risk factors for intraventricular haemorrhage in very low birth weight infants. Indian J Pediatr. 2002; 69:561-564. [PubMed: 12173693]

30. Ment LR, Oh W, Ehrenkranz RA, Philip AG, Duncan CC, Makuch RW. Antenatal steroids, delivery mode, and intraventricular hemorrhage in preterm infants. Am J Obstet Gynecol. 1995; 172:795-800. [PubMed: 7892866]

31. Dani C, Poggi C, Bertini G, Pratesi S, Di Tommaso M, Scarselli G, et al. Method of delivery and intraventricular haemorrhage in extremely preterm infants. J Matern-Fetal Neonatal Med. 2010; 23:1419-1423. [PubMed: 20236026]

32. Anand K, Hall RW, Desai N, Shephard B, Bergqvist LL, Young TE, et al. Effects of morphine analgesia in ventilated preterm neonates: primary outcomes from the NEOPAIN randomised trial. The Lancet. 2004; 363:1673-1682.

33. Lazzara A, Ahmann P, Dykes F, Brann AW, Schwartz J. Clinical predictability of intraventricular hemorrhage in preterm infants. Pediatrics. 1980; 65:30-34. [PubMed: 7355032]

34. Vesoulis ZA, Liao SM-C, Trivedi S, El Ters N, Mathur AM. A Novel Method for Assessing Cerebral Autoregulation in Preterm Infants Using Transfer Function Analysis. Pediatr Res. 
35. Soul JS, Hammer PE, Tsuji M, Saul JP, Bassan H, Limperopoulos C, et al. Fluctuating pressurepassivity is common in the cerebral circulation of sick premature infants. Pediatr Res. 2007; 61:467-473. [PubMed: 17515873]

36. Noori S, McCoy M, Anderson MP, Ramji F, Seri I. Changes in Cardiac Function and Cerebral Blood Flow in Relation to Peri/Intraventricular Hemorrhage in Extremely Preterm Infants. J Pediatr. 2014; 164:264-270.e3. [PubMed: 24183212]

37. Wollner L, McCarthy ST, Soper ND, Macy DJ. Failure of cerebral autoregulation as a cause of brain dysfunction in the elderly. Br Med J. 1979; 1:1117-1118. [PubMed: 444957]

38. Watterberg KL, Scott SM. Evidence of early adrenal insufficiency in babies who develop bronchopulmonary dysplasia. Pediatrics. 1995; 95:120-125. [PubMed: 7770288]

39. Bajwa N, Berner M, Worley S, Pfister R. Population based age stratified morbidities of premature infants in Switzerland. Swiss Med Wkly. 2011 
A

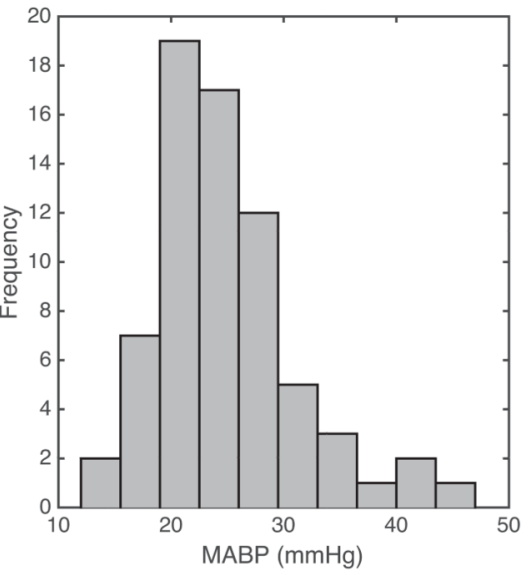

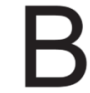

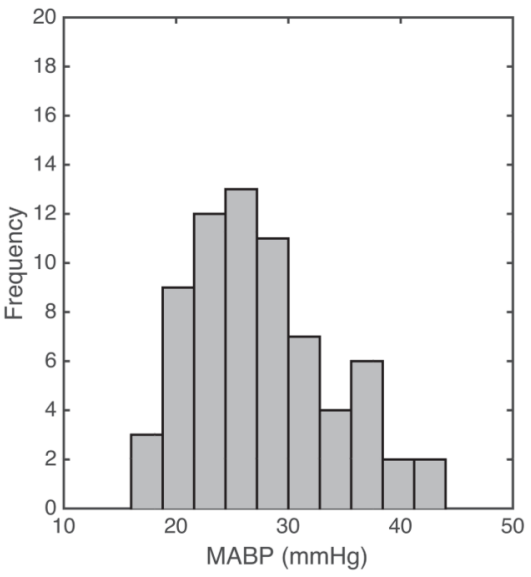

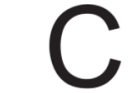

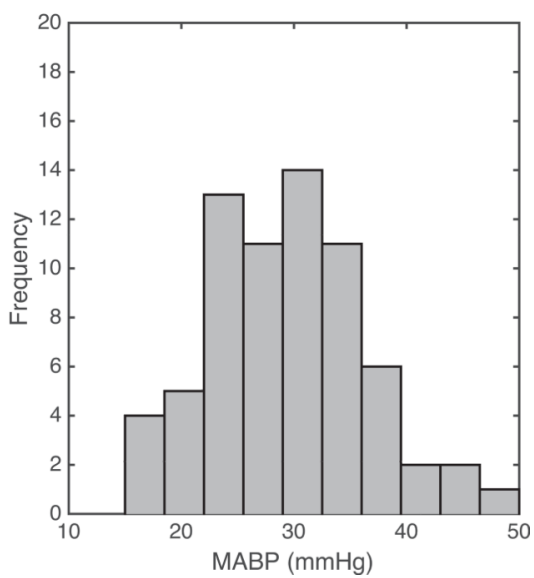

Figure 1.

Histograms are shown demonstrating the distribution of measured MABP values at dopamine treatment start (panel A) as well as one hour (panel B) and three hours (panel C) later. Note the transition from a right-skewed to a somewhat normal distribution over this time interval. 
Table 1

Descriptive statistics of sample

\begin{tabular}{|c|c|c|c|}
\hline & $\begin{array}{r}\text { No dopamine } \\
(n=46)\end{array}$ & $\begin{array}{r}\text { Dopamine } \\
(n=69)\end{array}$ & $P$ value \\
\hline Gestational age at birth, mean $\pm S D$, weeks & $25.1(1.0)$ & $24.8(1.3)$ & 0.13 \\
\hline Birth weight, mean $\pm S D$, grams & $811.9(230.9)$ & $780.3(230.9)$ & 0.09 \\
\hline Male sex, $n(\%)$ & $29(63)$ & $43(62)$ & 1.0 \\
\hline African-American race, $n(\%)$ & $21(46)$ & $36(52)$ & 0.57 \\
\hline SGA, $n(\%)$ & $2(4)$ & $5(7)$ & 0.7 \\
\hline \multicolumn{4}{|l|}{ Antenatal steroids } \\
\hline None, $n(\%)$ & $12(26)$ & $26(38)$ & 0.23 \\
\hline Complete course, $n(\%)$ & $22(48)$ & $41(59)$ & 0.21 \\
\hline Chorioamnionitis $^{a}, n(\%)$ & $18(39)$ & $7(10)$ & $<0.01^{*}$ \\
\hline Antenatal magnesium sulfate exposure, $n(\%)$ & $20(43)$ & $37(54)$ & 0.34 \\
\hline Vaginal delivery, $n(\%)$ & $18(39)$ & $15(22)$ & 0.06 \\
\hline Mechanical ventilation at $72 \mathrm{~h}, n(\%)$ & $35(76)$ & $59(85)$ & 0.22 \\
\hline Fentanyl exposure, $n(\%)$ & $17(37)$ & $40(58)$ & $0.03 *$ \\
\hline PDA requiring treatment, $n(\%)$ & $23(50)$ & $26(38)$ & 0.25 \\
\hline \multicolumn{4}{|l|}{ IVH } \\
\hline All grades, $n(\%)$ & $19(41)$ & $47(68)$ & $<0.01 *$ \\
\hline Grade III-IV, $n(\%)$ & $7(15)$ & $28(41)$ & $<0.01 *$ \\
\hline Died in the neonatal period, $n(\%)$ & $4(9)$ & $20(29)$ & $<0.01 *$ \\
\hline CRIB-II score, median (min-max) & $12(9-16)$ & $13(8-20)$ & $<0.01 *$ \\
\hline Postnatal age at start, mean $\pm S E M$, hours & $17.8(1.1)$ & $17.8(2.1)$ & 0.89 \\
\hline NS bolus prior to dopamine initiation, $n(\%)$ & $0(0)$ & $16(23)$ & $\mathrm{n} / \mathrm{a}$ \\
\hline Dopamine infusion dose at start, median (min-max), $\mu \mathrm{g} / \mathrm{kg} / \mathrm{min}$ & 0 & $2.5(1-7.5)$ & $\mathrm{n} / \mathrm{a}$ \\
\hline Dopamine infusion dose at end, median (min-max), $\mu \mathrm{g} / \mathrm{kg} / \mathrm{min}$ & 0 & $2.5(1-10)$ & $\mathrm{n} / \mathrm{a}$ \\
\hline
\end{tabular}

'Based on histologic examination of the placenta. Comparisons made using Mann-Whitney U-test for continuous variables or Fisher's Exact Test (two-sided) for categorical variables.

NS-normal saline. 


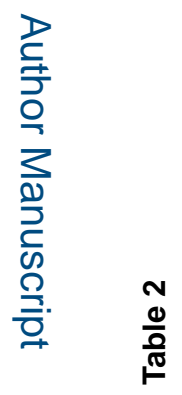

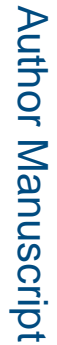

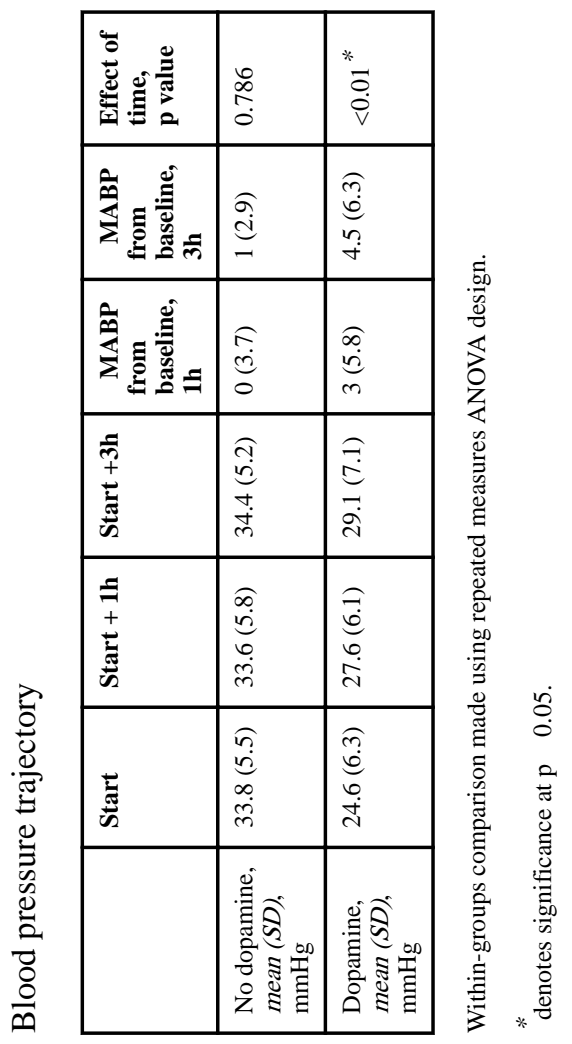

J Perinatol. Author manuscript; available in PMC 2016 August 18. 


\begin{tabular}{|c|c|c|c|c|c|c|c|c|c|}
\hline \multirow{3}{*}{ 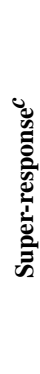 } & $\frac{5}{7}$ & $\stackrel{+}{-}$ & $\stackrel{n}{=}$ & $\stackrel{?}{-}$ & $\exists$ & $=$ & $\exists$ & $\stackrel{ \pm}{-}$ & $\stackrel{?}{?}$ \\
\hline & 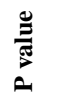 & $\hat{\tilde{c}}$ & 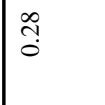 & $\stackrel{n}{0}$ & $\hat{o}$ & $\stackrel{9}{0}$ & గి & $\overline{\widehat{\jmath}}$ & $\stackrel{0}{0}$ \\
\hline & 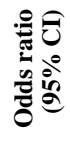 & 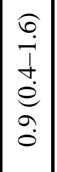 & 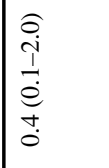 & $\begin{array}{l}\text { ì } \\
\hat{i} \\
\grave{e} \\
\text { d } \\
\text { d. }\end{array}$ & 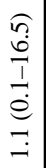 & 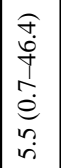 & 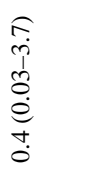 & 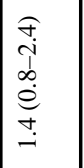 & 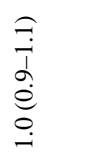 \\
\hline \multirow{3}{*}{ 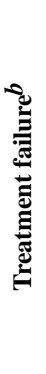 } & $\frac{5}{5}$ & $\exists$ & $\stackrel{\sim}{=}$ & $\stackrel{?}{-}$ & $\exists$ & $\exists$ & $\exists$ & $\stackrel{\simeq}{=}$ & $\stackrel{\text { I }}{=}$ \\
\hline & A & 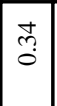 & $\hat{\imath}$ & $\begin{array}{l}* \\
{ }^{*} \\
\dot{0} \\
\dot{0} \\
v\end{array}$ & \begin{tabular}{l}
0 \\
$\stackrel{\infty}{\infty}$ \\
\hdashline
\end{tabular} & 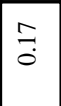 & 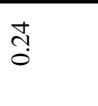 & $\frac{n}{0}$ & $\stackrel{\circ}{\circ}$ \\
\hline & 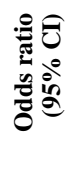 & 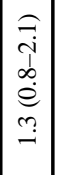 & $\begin{array}{l}\widehat{c} \\
\hat{1} \\
\hat{1} \\
\hat{e} \\
\infty \\
0 \\
0\end{array}$ & $\begin{array}{l}0 \\
0 \\
0 \\
1 \\
0 \\
0 \\
0 \\
0\end{array}$ & 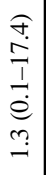 & $\begin{array}{c}\tilde{n} \\
i \\
i \\
\delta \\
o \\
e \\
o \\
0 \\
0\end{array}$ & 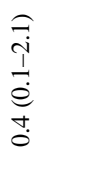 & 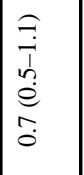 & 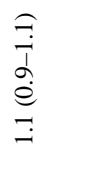 \\
\hline \multirow{3}{*}{ 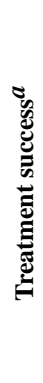 } & $\mathrm{g}$ & $\exists$ & $\exists$ & $\stackrel{\Upsilon}{\Im}$ & $\exists$ & $\exists$ & $\exists$ & $=$ & $\Xi$ \\
\hline & A & 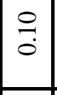 & $\stackrel{a}{\stackrel{a}{0}}$ & $\stackrel{n}{0}$ & $\begin{array}{l}0 \\
0 \\
0\end{array}$ & ปี & ñ & $\begin{array}{l}0 \\
0 \\
0\end{array}$ & $\stackrel{m}{0}$ \\
\hline & 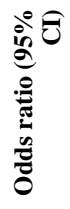 & 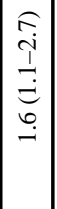 & $\begin{array}{l}\hat{\sigma} \\
\hat{i} \\
\hat{e} \\
\hat{o} \\
\text { ò }\end{array}$ & 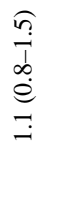 & 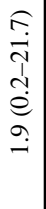 & 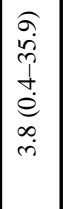 & 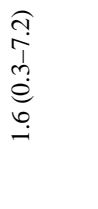 & 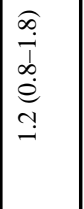 & 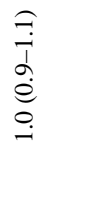 \\
\hline & & \begin{tabular}{|l|} 
\\
0 \\
\end{tabular} & 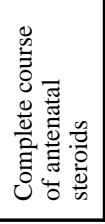 & 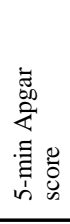 & 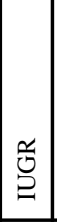 & 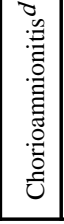 & 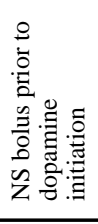 & 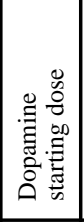 & 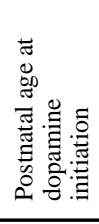 \\
\hline
\end{tabular}

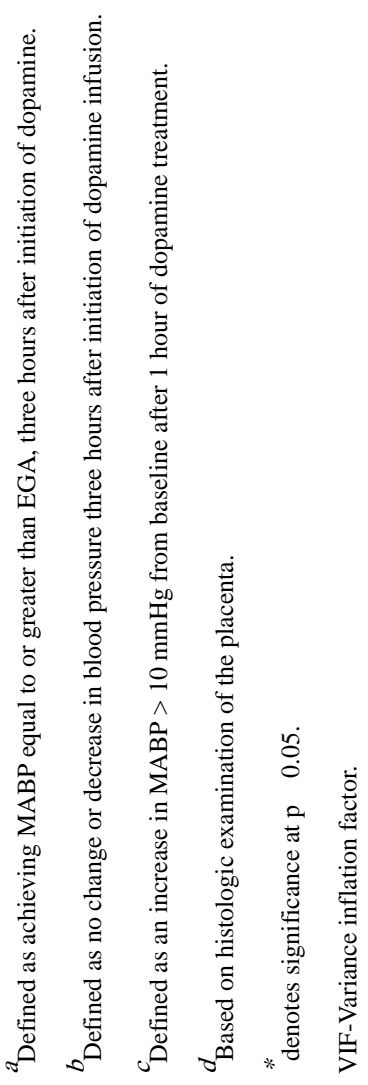

J Perinatol. Author manuscript; available in PMC 2016 August 18. 


\begin{tabular}{|c|c|c|c|c|c|c|c|c|c|c|c|c|c|c|c|c|}
\hline \multirow{3}{*}{ 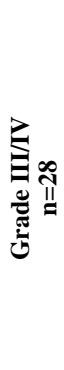 } & $\frac{\pi}{2}$ & $\dot{m}$ & $\stackrel{\bullet}{i}$ & $\stackrel{ \pm}{-}$ & $\exists$ & $\stackrel{?}{-}$ & $\stackrel{ \pm}{-}$ & $\stackrel{\Xi}{-}$ & $\stackrel{ \pm}{-}$ & $\Xi$ & $\stackrel{n}{n}$ & $\stackrel{\simeq}{=}$ & $\stackrel{?}{-}$ & $\stackrel{ \pm}{-}$ & $\stackrel{n}{=}$ & $\stackrel{?}{=}$ \\
\hline & 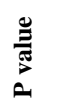 & $\begin{array}{l}\hat{2} \\
0\end{array}$ & $\begin{array}{l}: \\
: \\
0\end{array}$ & กิ & f & $\begin{array}{l}0 \\
0\end{array}$ & \begin{tabular}{l}
$\stackrel{0}{0}$ \\
\hdashline
\end{tabular} & $\stackrel{0}{0}$ & 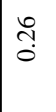 & $\begin{array}{l}* \\
* \\
0 \\
0\end{array}$ & $\begin{array}{l}\bar{\infty} \\
\dot{0}\end{array}$ & 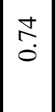 & $\mid \begin{array}{l}\tilde{O} \\
\hat{O}\end{array}$ & $\begin{array}{l}q \\
0 \\
0\end{array}$ & 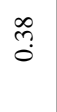 & " \\
\hline & 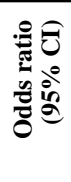 & 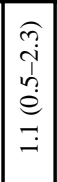 & 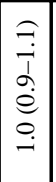 & $\begin{array}{l}\text { I } \\
\stackrel{I}{I} \\
\stackrel{0}{0} \\
\dot{0} \\
\dot{0}\end{array}$ & $\begin{array}{l}\widehat{T} \\
i \\
\frac{1}{0} \\
0 \\
0 \\
0 \\
0\end{array}$ & $\begin{array}{c}\hat{\imath} \\
\hat{i} \\
\hat{\sim} \\
e \\
\infty \\
0 \\
0\end{array}$ & 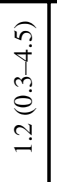 & 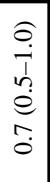 & 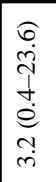 & 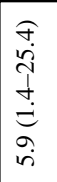 & $\begin{array}{l}\hat{\sigma} \\
\dot{d} \\
\tilde{N} \\
\stackrel{0}{0} \\
\infty \\
0\end{array}$ & 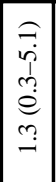 & 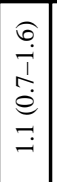 & 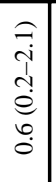 & $\begin{array}{l}6 \\
0 \\
0 \\
0 \\
0 \\
0 \\
a \\
-\end{array}$ & 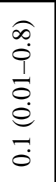 \\
\hline \multirow{3}{*}{ 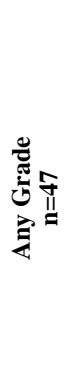 } & $\frac{1}{>}$ & $\vec{i}$ & $\vec{i}$ & $\stackrel{\infty}{-}$ & $\because$ & $\cong$ & $\stackrel{+}{-}$ & $\stackrel{?}{-}$ & $\because$ & 9 & $\stackrel{\grave{i}}{\mathrm{i}}$ & $\stackrel{?}{f}$ & $\stackrel{\Delta}{-}$ & $\stackrel{\Delta}{-}$ & $\cong$ & $\stackrel{?}{=}$ \\
\hline & 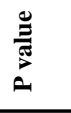 & $\begin{array}{l}0 \\
\tilde{m} \\
0\end{array}$ & $\begin{array}{l}\vdots \\
0 \\
0\end{array}$ & $\begin{array}{l}\stackrel{*}{0} \\
\stackrel{0}{0} \\
\dot{0} \\
v\end{array}$ & $\begin{array}{l}* \\
\stackrel{*}{\circ} \\
\end{array}$ & $\tilde{n}$ & $\frac{n}{0}$ & $\stackrel{\overbrace{}}{0}$ & $\stackrel{7}{0}$ & $\begin{array}{l}* \\
\text { *a } \\
\dot{0} \\
v\end{array}$ & $\begin{array}{l}* \\
\overrightarrow{0} \\
\dot{0} \\
v \\
\end{array}$ & 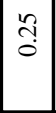 & $\left|\begin{array}{l}\infty \\
\stackrel{0}{0} \\
0\end{array}\right|$ & $\begin{array}{l}\text { I } \\
\text { O }\end{array}$ & 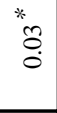 & $\stackrel{ \pm}{0}$ \\
\hline & 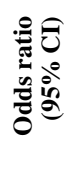 & 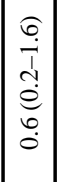 & 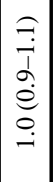 & $\begin{array}{l}0 \\
0 \\
0 \\
0 \\
0 \\
0 \\
0 \\
0\end{array}$ & $\begin{array}{c}\widehat{\alpha} \\
0 \\
1 \\
0 \\
0 \\
0 \\
0 \\
0\end{array}$ & 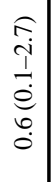 & $\begin{array}{c}0 \\
0 \\
\stackrel{1}{1} \\
0 \\
0 \\
0 \\
0\end{array}$ & 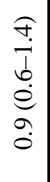 & 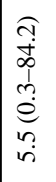 & 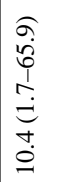 & $\begin{array}{c}0 \\
0 \\
0 \\
0 \\
0 \\
0 \\
0 \\
0\end{array}$ & 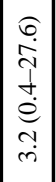 & $\begin{array}{l}\hat{\sigma} \\
\stackrel{j}{j} \\
\stackrel{0}{0} \\
\stackrel{0}{0}\end{array}$ & 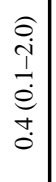 & 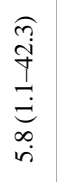 & 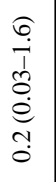 \\
\hline$\overline{3}$ & & \begin{tabular}{|l}
$\mathbb{J}$ \\
\end{tabular} & 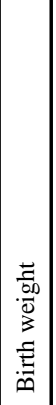 & 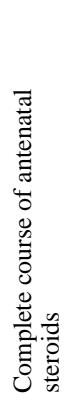 & 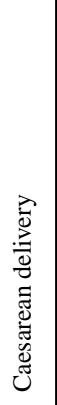 & 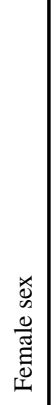 & 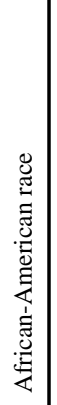 & 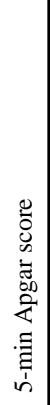 & 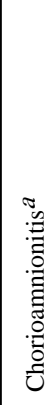 & 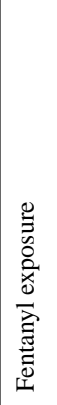 & 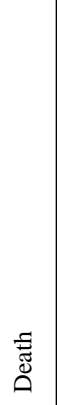 & 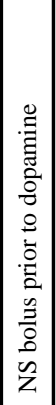 & 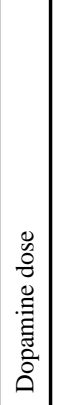 & 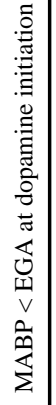 & 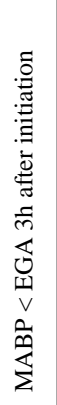 & 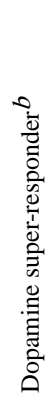 \\
\hline
\end{tabular}

